\title{
Survival and Surgical Complications in Anaplastic Thyroid Cancer Patients After Completed Multimodal Treatment
}

\author{
BIANCA LORNTZSEN ${ }^{1,2}$, ANNE-BIRGITTE JACOBSEN ${ }^{3}$, \\ KRYSTYNA K. GRØHOLT ${ }^{4}$, EVA SIGSTAD ${ }^{4}$ and TERJE OSNES ${ }^{1,2}$ \\ ${ }^{1}$ Faculty of Medicine, Institute of Clinical Medicine, University of Oslo, Oslo, Norway; \\ ${ }^{2}$ Department of Otorhinolaryngology, Head and Neck Surgery, Division of Head, \\ Neck and Reconstructive Surgery, Oslo University Hospital, Oslo, Norway; \\ ${ }^{3}$ Department of Oncology, Division of Cancer Medicine, Oslo University Hospital, Oslo, Norway; \\ ${ }^{4}$ Department of Pathology, Division of Laboratory Medicine, Oslo University Hospital, Oslo, Norway
}

\begin{abstract}
Background/Aim: This study aimed to examine survival and surgical complications in patients with anaplastic thyroid cancer (ATC) after multimodal treatment. Patients and Methods: Since 2002, the recommended treatment strategy for ATC at our centre has been hyperfractionated accelerated radiotherapy (HART) with high doses to the neck (64 Gy), combined with weekly doxorubicin, and surgery after 4-8 weeks, if feasible. Results: Between 2002 and 2014, 14 patients completed HART and thyroid surgery. Eight patients had preoperative HART, and six postoperative HART. Median survival was 20 months (range=4-110 months) in all patients, 51 months (range=4-110 months) and 18.5 months (range=956 months) in the preoperative and postoperative HART groups, respectively. Six patients survived for more than two years, and four patients survived for more than five years. Seven patients had postoperative complications. Conclusion: In this series of selected patients, an improved survival after aggressive, multimodal treatment was observed. Preoperative HART may promote survival although complications may be more frequent.
\end{abstract}

Anaplastic thyroid cancer (ATC) is one of the most aggressive forms of cancer $(1,2)$, and is often met with defeatist expectations. Median overall survival after diagnosis is reported to be 3.9 months and with multimodal treatment 10.5 months (1). Since 2002, the recommended

This article is freely accessible online.

Correspondence to: Bianca Lorntzsen (ORCID: 0000-0003-33243220), Faculty of Medicine, Institute of Clinical Medicine, University of Oslo, P.O box 1171 Blindern, 0318 Oslo, Norway. Tel: + 47 90087002, e-mail: b.m.lorntzsen@medisin.uio.no

Key Words: Anaplastic thyroid cancer, thyroid surgery, multimodal treatment, radiotherapy, hyperfractionated accelerated radiotherapy. treatment strategy for ATC at our center has been preoperative hyperfractionated accelerated radiotherapy (HART) with high total doses (64 Gy in four weeks) to the neck combined with weekly doxorubicin for eligible patients, followed by surgery 4-8 weeks later if feasible (3). By then, primary inoperable tumors may have shrunk to an operable level (Figure 1).

In 2002, a multidisciplinary team (MDT) for thyroid nodules and cancer was established, comprising oncologists, pathologists, radiologists, nuclear medicine physicians, endocrine surgeons and ear, nose and throat (ENT)/head and neck surgeons, meeting weekly. Patients with confirmed or suspected ATC are evaluated by the MDT and, because of the rapid tumor growth, radiotherapy (RT) is planned to start within a week following confirmation of the diagnosis. The MDT decides whether or not surgery can be performed 4-8 weeks after HART. Surgery aims to achieve a gross tumor resection.

A retrospective study of 31 ATC patients treated with HART with or without surgery at our institution, has previously been published, describing the chemoradiotherapy, toxicity, surgery, pathology review and treatment results (4). The current report documents the management and outcomes of a subgroup of 14 patients who completed treatment with HART and thyroid surgery for ATC, focusing on the role of surgery. The primary endpoint was survival, and the secondary endpoint was surgery-related complications.

\section{Patients and Methods}

We performed a retrospective, population-based cohort study on ATC patients treated with HART, doxorubicin and surgery at Oslo University Hospital during 2002-2014. Patients with ATC in the south-east region of Norway are usually referred to Oslo University Hospital. The population of the region at the time was 2.95 million inhabitants. Patients included in the current report had a confirmed diagnosis of ATC, with no evidence of distant metastases at the time of diagnosis, and were considered operable before or after HART. 


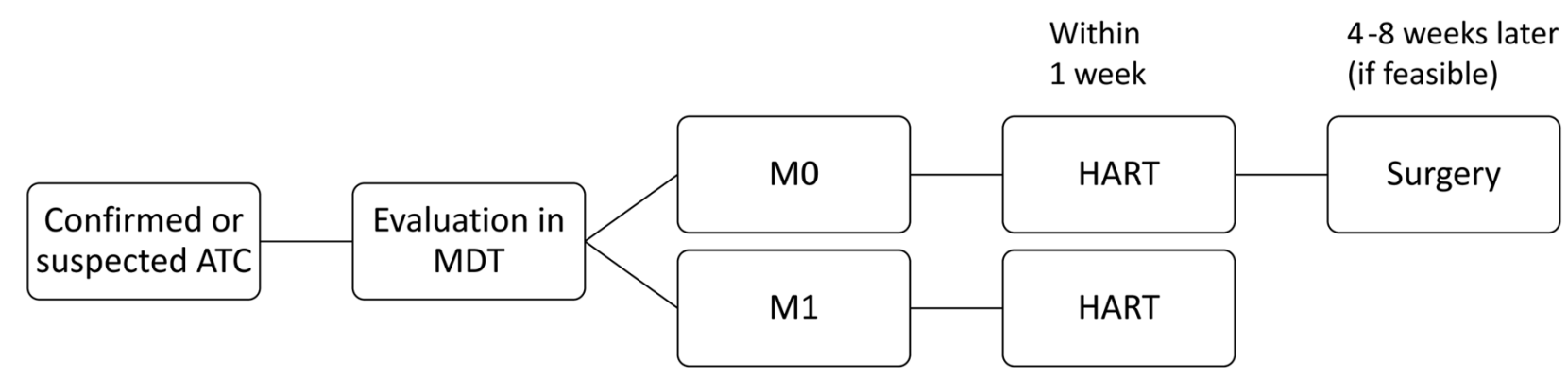

Figure 1. Treatment strategy for patients with ATC.

Observation time was from the date of diagnosis till death, or $31^{\text {st }}$ of December 2019 for living patients.

Diagnosis was determined by fine needle aspiration cytology (FNAC), core needle biopsy (CNB) or open biopsy from the thyroid gland and, in some cases, on the surgical specimen resected during surgery due to other preoperative diagnoses. Investigations included ultrasound and computed tomography (CT) of the neck, chest and abdominal CT, and in some cases also positron emission tomography (PET)/CT. Clinical data were retrieved from the patients' medical records. The American Joint Committee on Cancer's Cancer Staging Manual $7^{\text {th }}$ edition was used for TNM classifications (5). A histopathology review was performed by two senior thyroid pathologists.

HART was given to a dose of 64 Gy during a period of 4 weeks, with a fraction dose of 1.6 Gy two times per day. All patients had surgery with curative intent, comprising hemi- or total thyroidectomy in one or two stages. Extended surgery (ES) included thoracoscopic removal of mediastinal metastasis, mediastinal exploration, resection of the laryngeal and cricoid cartilage, and tracheal resection (TR) reconstructed with either end-to-end anastomosis (ETE) or a vascularized myoperiosteal flap. Lymph node dissection (LND) was either lateral- or central compartment-oriented, or modified radical LND. Surgical margins status was classified as no residual tumor (R0), microscopic residual tumor (R1) or macroscopic residual tumor (R2).

Postoperative complications included treatment for hematomas or bleeding related to primary or revision surgery. Postoperative infection was registered if antibiotic treatment for wound infection or pneumonia was administered. Revision surgery included procedures under general or local anesthesia. NED (no evidence of disease) was defined as no clinical or radiological evidence of anaplastic thyroid cancer. Status at the end of observation was recorded from the patients' medical records including autopsy reports and reports from local hospitals.

Data were stored in an SPSS (IBM Corp., Armonk, NY, USA) database according to hospital regulations. Descriptive statistics are presented as median values and ranges. Statistical comparisons were not performed due to the small population size. The study was approved by the Regional Ethics Committee.

\section{Results}

Fifty-one patients with ATC diagnosed in the period 20022014 were identified, of whom 31 received HART, the other
20 received other or palliative treatment. Seventeen patients received HART only, as they were considered not feasible for surgery, mainly due to distant metastases or a poor general condition. Among the 31 patients treated with HART, thirteen patients underwent surgery as part of the primary treatment, and one on a recurrence. We report on these 14 patients (Figure 2).

Characteristics of patients and tumors are summarized in Table I. An overview of the individual cases, including surgical treatment, surgical margins and complications is presented in Table II.

HART was completed in all patients with a median dose of 64 Gy (range=46-64 Gy). Six patients were operated on due to other preoperative diagnoses, such as goiter or papillary thyroid carcinoma. A diagnosis of ATC was made on the surgical specimen, and these six patients had postoperative HART. The time between HART and surgery was 4-8 weeks for 10 of 14 patients. In the remaining four patients, intervals were 10, 20, 21 and 93 weeks, due to revised histopathology, intercurrent disease and recurrent cancer.

Seven patients developed one or more complications after surgery. One patient had a fatal bleeding from the airways the day after decannulation. Three patients underwent revision surgeries for fistulas. Four patients had a tracheostomy during the course of the disease. Two of them were decannulated after 14 and 105 days, respectively. One patient acquired a bilateral recurrent laryngeal nerve paresis (RLNP) from thyroid surgery, and a tracheostomy until death five months later. One patient had a tracheostomy 18 months after thyroid surgery due to recurrent disease, and kept this until death two months later.

Median survival for the 14 patients was 20 months (range $=4-110$ months). Median survival was 51 (range $=4$ 110 months) and 18.5 months (range=9-56 months) in the preoperative and postoperative HART groups, respectively. Six patients survived for more than two years, four of whom had preoperative HART, and four with R0 resections. Four patients survived more than five years, all of whom had 


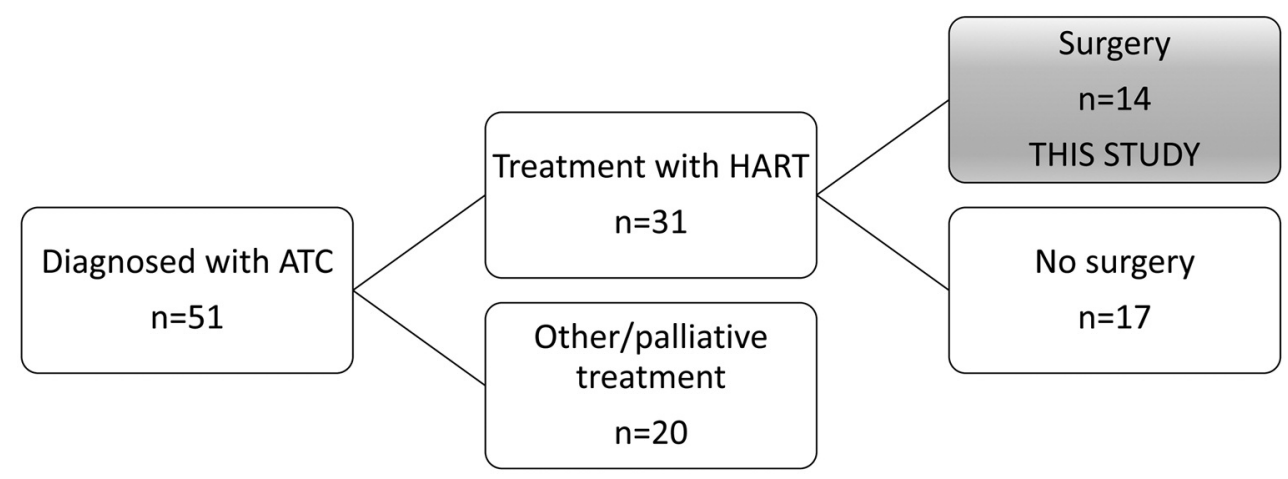

Figure 2. Flowchart of the patients included in this study.

Table I. Patient and tumor characteristics at diagnosis.

\begin{tabular}{lccc}
\hline & All patients $(\mathrm{n}=14)$ & Preoperative HART $(\mathrm{n}=8)$ & Postoperative HART $(\mathrm{n}=6)$ \\
\hline Age in years, median (range) & $67.5(52-86)$ & $64(52-77)$ & $72.5(62-86)$ \\
Male/female ratio & $7 / 7$ & $3 / 5$ & $4 / 2$ \\
Stage IVA/IVB & $2 / 12$ & $1 / 7$ & $1 / 5$ \\
WHO performance status 0/1 & $11 / 3$ & $5 / 3$ & $6 / 0$ \\
\hline
\end{tabular}

HART: Hyperfractionated accelerated radiotherapy; WHO: World Health Organization.

preoperative HART. At the end of observation, two patients were alive. Survival data are shown in Table III.

\section{Discussion}

Aggressive multimodal treatment of ATC patients showed an acceptable survival in our cohort of patients. A tendency towards a longer survival among patients with preoperative HART was seen, where 4 of 8 patients survived 5 years or more.

The question whether surgery should be performed before or after RT for ATC remains a matter of debate (6). The American Thyroid Association recommends surgery followed by RT with or without chemotherapy for stage IVA and IVB if the disease is considered resectable. In cases of unresectable stage IVB disease, RT with or without chemotherapy followed by surgery is recommended (2). A review published by Are et. al in 2006 cited studies showing that preoperative RT may help to increase the resectability rate (7) congruent with the rationale behind our treatment strategy.

Studies indicate that complete resection (R0/R1) for ATC is associated with prolonged disease-free survival and overall survival $(2,8)$. Since all surgical procedures in our series were performed with curative intent, we aimed at gross resection of the tumor. Among the two-year survivors, four of six patients had free surgical margins. Deviation from our treatment strategy of 4-8 weeks between RT and surgery occurred in four cases. However, no clear negative influence was seen among the patients with a longer time interval between RT and surgery.

Comparable studies related to RT and surgical treatment of ATC are summarized in Table IV, of which the majority relate to patients treated with postoperative RT. The median survival observed in our patients is in accordance with that in these studies. A longer survival for patients given higher doses of RT was seen in several studies (9-11). In our cohort, all patients completed treatment including high doses to the neck, with a median dose of 64 Gy (range=46-64 Gy).

Few studies present data on HART and surgery, more often with lower RT doses, and in these, the median survival was shorter than in our study $(3,11)$. As for pre- versus postoperative HART, we found a higher proportion of 2- and 5year survivors among patients with preoperative HART.

A study by Fan et al. showed significantly improved overall survival (OS) and locoregional progression-free survival (LPFS) in patients receiving trimodal ATC treatment with RT doses $>60$ Gy (12). A large cohort of 677 ATC cases reported by Sugitani showed significantly improved survival in patients in with RT doses $>40$ Gy compared to doses $\leq 40$ Gy, and in patients receiving radical surgery versus no or 
Table II. Overview of patients.

\begin{tabular}{|c|c|c|c|c|c|c|c|c|}
\hline Pat no & TNM & $\begin{array}{c}\text { Pre-/ } \\
\text { postoperative } \\
\text { HART }(\mathrm{Gy})\end{array}$ & $\mathrm{R}$ & $\begin{array}{l}\text { Observation } \\
\text { time }\end{array}$ & $\begin{array}{c}\text { Status at end } \\
\text { of observation } \\
31.12 .19\end{array}$ & Surgery & $\begin{array}{l}\text { Extended } \\
\text { surgery }\end{array}$ & Complications \\
\hline 1 & T4aN1bM0 & $\begin{array}{c}\text { Pre } \\
(57.6 \mathrm{~Gy})\end{array}$ & R0 & 106 & Dead, NED & TT, LND & & \\
\hline 2 & T4bN0M0 & $\begin{array}{c}\operatorname{Pre}^{\dagger} \\
(64 \mathrm{~Gy})\end{array}$ & R0 & 110 & Alive, NED & $\mathrm{TT}$ & Thoracoscopy & Infection \\
\hline 3 & T4bN0M0 & $\begin{array}{c}\text { Pre } \\
(64 \text { Gy) }\end{array}$ & R0 & 98 & Alive, NED & TT, LND & & \\
\hline 4 & T4bNXM0 & $\begin{array}{c}\text { Pre } \\
(63.2 \mathrm{~Gy})\end{array}$ & R0 & 14 & $\begin{array}{l}\text { Dead with distant } \\
\text { metastases }\end{array}$ & TT, LND & $\begin{array}{l}\text { Exploration } \\
\text { mediastinum }\end{array}$ & \\
\hline 5 & T4bN0M0 & $\begin{array}{c}\text { Pre } \\
\text { (64 Gy) }\end{array}$ & $\mathrm{R} 1$ & 81 & Dead, NED & HT, LND & & $\begin{array}{c}\text { Infection } \\
\text { Hematoma } \\
\text { Revision surgery }\end{array}$ \\
\hline 6 & T4bN0M0 & $\begin{array}{c}\text { Pre } \\
(46 \mathrm{~Gy})\end{array}$ & $\mathrm{R} 1$ & 21 & $\begin{array}{l}\text { Dead with distant } \\
\text { metastases }\end{array}$ & TT, LND & & $\begin{array}{c}\text { Infection } \\
\text { Revision surgery } \\
\text { Pulmonary embolism }\end{array}$ \\
\hline 7 & T4bN1bM0 & $\begin{array}{c}\text { Pre } \\
(64 \mathrm{~Gy})\end{array}$ & $\mathrm{R} 1$ & 18 & $\begin{array}{l}\text { Dead with distant } \\
\text { metastases }\end{array}$ & HT, LND & $\begin{array}{l}\text { TR reconstructed } \\
\text { with myo- } \\
\text { periosteal flap }\end{array}$ & $\begin{array}{l}\text { Infection } \\
\text { Pleural effusion } \\
\text { Revision surgery } \\
\text { Unilateral RLNP }\end{array}$ \\
\hline 8 & T4bNOM0 & $\begin{array}{c}\text { Pre } \\
(64 \text { Gy) }\end{array}$ & $\mathrm{R} 1$ & 4 & $\begin{array}{c}\text { Dead with local } \\
\text { disease }\end{array}$ & TT, LND & & $\begin{array}{c}\text { Infection } \\
\text { Lethal bleeding }\end{array}$ \\
\hline 9 & T4aN1bM0 & $\begin{array}{l}\text { Post } \\
(64 \text { Gy) }\end{array}$ & R0 & 45 & $\begin{array}{c}\text { Dead with local } \\
\text { disease and distant } \\
\text { metastases }\end{array}$ & TT, LND & & \\
\hline 10 & T4bN1bM0 & $\begin{array}{l}\text { Post } \\
\text { (64 Gy) }\end{array}$ & R0 & 19 & $\begin{array}{c}\text { Dead with local } \\
\text { disease }\end{array}$ & TT, LND & & Chyle leak \\
\hline 11 & $\mathrm{~T} 4 \mathrm{bN} 1 \mathrm{M} 0$ & $\begin{array}{c}\text { Post } \\
\text { (64 Gy) }\end{array}$ & $\mathrm{R} 2$ & 56 & $\begin{array}{l}\text { Dead with distant } \\
\text { metastases }\end{array}$ & HT & & \\
\hline 12 & T4bN1bM0 & $\begin{array}{l}\text { Post } \\
\text { (64 Gy) }\end{array}$ & $\mathrm{R} 1$ & 18 & $\begin{array}{c}\text { Dead with local } \\
\text { disease and distant } \\
\text { metastases }\end{array}$ & TT, LND & $\begin{array}{l}\text { Partial resection } \\
\text { of thyroid and } \\
\text { cricoid cartilage }\end{array}$ & \\
\hline 13 & T4bNXM0 & $\begin{array}{c}\text { Post } \\
(64 \mathrm{~Gy})\end{array}$ & $\mathrm{R} 1$ & 15 & $\begin{array}{l}\text { Dead with distant } \\
\text { metastases }\end{array}$ & $\mathrm{TT}$ & & \\
\hline 14 & T4bN1bM0 & $\begin{array}{c}\text { Post } \\
\text { (64 Gy) }\end{array}$ & R2 & 9 & $\begin{array}{l}\text { Dead with distant } \\
\text { metastases }\end{array}$ & TT & $\begin{array}{l}\text { TR reconstructed } \\
\text { with ETE }\end{array}$ & $\begin{array}{c}\text { Infection } \\
\text { Bilateral RLNP }\end{array}$ \\
\hline
\end{tabular}

HART: Hyperfractionated accelerated radiotherapy; Gy: Gray; R: surgical margin; NED: clinically no evidence of disease; HT: hemithyroidectomy; TT: total thyroidectomy; LND: lymph node dissection; TR: tracheal resection; ETE: end-to-end anastomosis; RLNP: recurrent laryngeal nerve palsy. †Treated surgically for recurrence 93 weeks after HART.

palliative surgery. In the same study, a significant benefit for survival was found in patients with stage lVB disease treated with surgery, chemotherapy and RT, as opposed to stage IVA patients who benefited only from radical surgery and RT $>40$ Gy (13).

The majority of complications in our study occurred in patients with preoperative HART. Few studies present surgical complications after treatment of ATC. In a study by Derbel et al. evaluating 44 patients with surgery for ATC, ten patients acquired a unilateral RLNP and four patients had hemorrhage at the surgical site (14). That study reports a lower rate of complications than that in our cohort, but refers to surgery with postoperative RT. High doses of RT renders tissue prone to impaired healing. The patient who underwent surgery 93 weeks after HART, was retained in the preoperative HART group, as the patient was expected to be prone to complications in a similar way as the other patients who had preoperative HART. This illustrates the importance of a thorough evaluation of the patients' ability to undergo demanding treatment by the MDT.

A compromised airway in ATC patients is a recognized issue due to the risk of bleeding and obstruction, as well as the impact on quality of life. In the large series by Sugitani et al., $80 \mathrm{lVB}$ patients underwent surgery, including 20 with extended radical surgery. $27 \%$ of patients who underwent regular surgery and $70 \%$ of patients with extended radical 
Table III. Survival in all patients, according to resection margins and preoperative or postoperative HART.

\begin{tabular}{lccccc}
\hline & Preoperative HART $(\mathrm{n}=8)$ & Postoperative HART $(\mathrm{n}=6)$ & $\mathrm{R} 0(\mathrm{n}=6)$ & $\mathrm{R} 1 / 2(\mathrm{n}=8)$ & All patients $(\mathrm{n}=14)$ \\
\hline Survival $>$ 1 year & 7 & 5 & 6 & 6 & 12 \\
Survival $>$ years & 4 & 2 & 4 & 2 & 6 \\
Survival $>$ 5years & 4 & 0 & 3 & 1 & 4 \\
$\begin{array}{l}\text { Survival in months, } \\
\text { median (range) }\end{array}$ & $51(4-110)$ & $18.5(9-56)$ & $71.5(14-110)$ & $18(4-81)$ & $20(4-110)$ \\
\hline
\end{tabular}

ATC: Anaplastic thyroid cancer; HART: hyperfractionated accelerated radiotherapy.

Table IV. Overview of articles regarding ATC patients treated with radiotherapy and surgery for comparison.

\begin{tabular}{|c|c|c|c|c|c|}
\hline $\begin{array}{l}\text { Author, } \\
\text { year }\end{array}$ & $\begin{array}{l}\text { Total no. } \\
\text { pts in study }\end{array}$ & $\begin{array}{l}\text { No. of pts with } \\
\text { surgery and RT }\end{array}$ & $\begin{array}{l}\text { Type } \\
\text { RT }\end{array}$ & $\begin{array}{l}\text { Distant metastasis } \\
\text { at diagnosis }\end{array}$ & $\begin{array}{l}\text { Survival and } \\
\text { comments }\end{array}$ \\
\hline Tennvall 2002 (3) & 55 & 40 & $\begin{array}{l}\text { Preoperative HART } 30-46 \mathrm{~Gy} \\
\pm \text { postoperative HART } 0-16 \mathrm{~Gy}\end{array}$ & 7 of 40 patients & $\begin{array}{l}\text { MS 2-4.5 months } \\
\text { depending on protocol }\end{array}$ \\
\hline Glaser 2016 (10) & 3552 & $\sim 5 \%$ of 3552 & High-dose RT > 59.4 Gy & No & $\begin{array}{c}\text { MS } 16 \text { months } \\
\text { among the 5\% } \\
\text { 2-year survival } 38 \%\end{array}$ \\
\hline $\begin{array}{l}\text { Swaak-Kragten } \\
2009 \text { (11) }\end{array}$ & 75 & 17 & $\begin{array}{c}\text { Postoperative Hyperfractionated } \\
\text { RT } 50.6 \mathrm{~Gy}\end{array}$ & No & $\begin{array}{l}\text { MS } 5 \text { months } \ddagger \\
\text { Surgery included biopsy, } \\
\text { thyroidectomy } \\
\text { and debulking }\end{array}$ \\
\hline DeCrevoisier & 30 & 20 & Postoperative RT & No & MS 18.5 months \\
\hline $2004(16)$ & & & $40 \mathrm{~Gy}$ & & $\begin{array}{c}3 \text { patients received } \\
\text { preoperative RT }\end{array}$ \\
\hline Brown 2013 (17) & 38 & 14 & Postoperative RT 50-70 Gy & No & $\begin{array}{l}7 \text { of } 14 \text { patients alive } \\
\text { with mean FU } 4.8 \text { years } \\
12 \text { of } 14 \text { patients LGT }\end{array}$ \\
\hline Foote 2011(9) & 25 & 10 & Postoperative RT 57.6-70 Gy & No & $\begin{array}{c}\text { OS } 60 \text { months } \\
\text { OS at } 1 \text { and } 2 \text { yrs at } \\
70 \% \text { and } 60 \%\end{array}$ \\
\hline Haymart 2013 (18) & 2742 & $\begin{array}{l}\text { IVA: } 96 \\
\text { IVB: } 79\end{array}$ & Yes, not further defined & No & $\begin{array}{l}\text { IVA: MS } 11.2 \text { months }^{\S} \\
\text { IVB: MS } 9.9 \text { months }\end{array}$ \\
\hline Fan 2019 (12) & 104 & 63 & $\begin{array}{l}\text { Postoperative RT median } \\
\text { dose } 66 \mathrm{~Gy} \text { (range=6-70.25) }\end{array}$ & $\begin{array}{l}23 \text { of } 104 \text { patients } \\
\text { (whereof } 6 \\
\text { with surgery) }\end{array}$ & $\begin{array}{l}\text { 1-year OS } 34.4 \% \\
\text { 1-year LPFS } 74.4 \% \\
\text { RT>60Gy associated } \\
\text { with improved } \\
\text { OS and LPFS }\end{array}$ \\
\hline Prasongsook 2017(19) & 48 & 27 (of 30) & $\begin{array}{l}\text { Postoperative RT } \\
66 \text { Gy (range }=46-70)\end{array}$ & 6 of 30 & Median OS $21 \mathrm{mos}$ \\
\hline
\end{tabular}

ATC: Anaplastic thyroid cancer; Pts: patients; RT: radiotherapy; HART: hyperfractionated accelerated radiotherapy; MS: median survival; Yrs: years; FU, follow up; LGT: laryngectomy; OS: overall survival; LPFS: locoregional progression-free survival. ¥Median survival calculated from table in article. §Overall survival if chemotherapy+RT. Somewhat lower without chemotherapy.

surgery needed permanent tracheostomy (13). In our study, $28 \%$ had a tracheostomy, whereof in $14 \%$ remained permanent.

An important aspect in our study was that the government provides equal access to recommended treatment. The close collaboration between specialties in the MDT facilitates an efficient and tailored treatment for each patient despite the challenging diagnosis. We have a fast track for ATC patients. A study by Hvilsom et al. showed that after introduction of the fast track program in Denmark for Head- and Neckcancer patients, the 1- and 5-year survival among ATC patients improved significantly (15). A major strength of our study is that a thorough pathology review was performed by two senior thyroid pathologists to avoid possible 
misdiagnosis leading to falsely improved survival. A limitation of this study is the small number of patients and the retrospective nature of the analysis. Our material is strongly selected, as many patients with ATC were not feasible for surgery due to distant metastatic disease or poor general condition. There were deviations from our management strategy, due to intercurrent health conditions and the less aggressive preoperative diagnoses. With five patients undergoing extensive surgery, there is heterogeneity in surgical treatment. With a limited number of patients, it is difficult to generalize on survival and morbidity. Larger studies are needed to gain further knowledge, and due to the rarity of the disease, a multicenter study could be considered.

The course of the disease is often complicated, and this reflects the need for individualized treatment planned and executed by MDTs.

\section{Conclusion}

Our study on a small number of selected patients with ATC indicates an improved survival after aggressive, multimodal treatment. A completed treatment may be an indication of a better prognosis. Surgery is possible after RT with high doses, and preoperative HART may be advantageous for better survival, although complications may be more frequent.

\section{Conflicts of Interest}

The Authors declare no conflicts of interest in relation to this study.

\section{Authors' Contributions}

BL have contributed to data collection, analysis and writing of the manuscript. ABJ contributed to the conception, design of the study, data collection, analysis and writing of the manuscript. TO contributed to conception, design of the study, analysis and writing of the manuscript. KKG and ES contributed to histology review. All coauthors have approved the final version of the manuscript.

\section{References}

1 Bisof V, Rakusic Z and Despot M: Treatment of patients with anaplastic thyroid cancer during the last 20 years: Whether any progress has been made? Eur Arch Otorhinolaryngol 272(7): 1553-1567, 2015. PMID: 24890977. DOI: 10.1007/s00405-0143108-1

2 Smallridge RC, Ain KB, Asa SL, Bible KC, Brierley JD, Burman KD, Kebebew E, Lee NY, Nikiforov YE, Rosenthal MS, Shah MH, Shaha AR and Tuttle RM: American thyroid association guidelines for management of patients with anaplastic thyroid cancer. Thyroid 22(11): 1104-1139, 2012. PMID: 23130564. DOI: 10.1089/thy.2012.0302

3 Tennvall J, Lundell G, Wahlberg P, Bergenfelz A, Grimelius L, Akerman M, Hjelm Skog AL and Wallin G: Anaplastic thyroid carcinoma: Three protocols combining doxorubicin, hyperfractio- nated radiotherapy and surgery. Br J Cancer 86(12): 1848-1853, 2002. PMID: 12085174. DOI: $10.1038 /$ sj.bjc.6600361

4 Jacobsen AB, Groholt KK, Lorntzsen B, Osnes TA, Falk RS and Sigstad E: Anaplastic thyroid cancer and hyperfractionated accelerated radiotherapy (hart) with and without surgery. Eur Arch Otorhinolaryngol 274(12): 4203-4209, 2017. PMID: 29019001. DOI: 10.1007/s00405-017-4764-8

5 Cancer TAJCo: AJCC cancer staging handbook 7th edition. 7 edn. Springer-Verlag New York: New York, NY, USA, 2010.

6 Smallridge RC: Approach to the patient with anaplastic thyroid carcinoma. J Clin Endocrinol Metab 97(8): 2566-2572, 2012. PMID: 22869844. DOI: $10.1210 /$ jc.2012-1314

7 Are C and Shaha AR: Anaplastic thyroid carcinoma: Biology, pathogenesis, prognostic factors, and treatment approaches. Ann Surg Oncol 13(4): 453-464, 2006. PMID: 16474910. DOI: $10.1245 /$ aso. 2006.05 .042

8 Kasmann L, Bolm L, Janssen S and Rades D: Prognostic factors for survival in patients treated with multimodal therapy for anaplastic thyroid cancer. Anticancer Res 36(9): 4697-4700, 2016. PMID: 27630315. DOI: 10.21873/anticanres.11023

9 Foote RL, Molina JR, Kasperbauer JL, Lloyd RV, McIver B, Morris JC, Grant CS, Thompson GB, Richards ML, Hay ID, Smallridge RC and Bible KC: Enhanced survival in locoregionally confined anaplastic thyroid carcinoma: A single-institution experience using aggressive multimodal therapy. Thyroid 21(1): 25-30, 2011. PMID: 21162687. DOI: 10.1089/thy.2010.0220

10 Glaser SM, Mandish SF, Gill BS, Balasubramani GK, Clump DA and Beriwal S: Anaplastic thyroid cancer: Prognostic factors, patterns of care, and overall survival. Head Neck 38(Suppl 1): E2083-2090, 2016. PMID: 26894506. DOI: 10.1002/hed.24384

11 Swaak-Kragten AT, de Wilt JH, Schmitz PI, Bontenbal M and Levendag PC: Multimodality treatment for anaplastic thyroid carcinoma - treatment outcome in 75 patients. Radiother Oncol 92(1): 100-104, 2009. PMID: 19328572. DOI: 10.1016/j.radonc. 2009.02.016

12 Fan D, Ma J, Bell AC, Groen AH, Olsen KS, Lok BH, Leeman JE, Anderson E, Riaz N, McBride S, Ganly I, Shaha AR, Sherman EJ, Tsai CJ, Kang JJ and Lee NY: Outcomes of multimodal therapy in a large series of patients with anaplastic thyroid cancer. Cancer 126(2): 444-452, 2020. PMID: 31593317. DOI: $10.1002 / \mathrm{cncr} .32548$

13 Sugitani I, Miyauchi A, Sugino K, Okamoto T, Yoshida A and Suzuki S: Prognostic factors and treatment outcomes for anaplastic thyroid carcinoma: Atc research consortium of Japan cohort study of 677 patients. World J Surg 36(6): 1247-1254, 2012. PMID: 22311136. DOI: 10.1007/s00268-012-1437-z

14 Derbel O, Limem S, Segura-Ferlay C, Lifante JC, Carrie C, Peix JL, Borson-Chazot F, Bournaud C, Droz JP and de la Fouchardiere C: Results of combined treatment of anaplastic thyroid carcinoma (atc). BMC Cancer 11: 469, 2011. PMID: 22044775. DOI: $10.1186 / 1471-2407-11-469$

15 Hvilsom GB, Londero SC, Hahn CH, Schytte S, Pedersen HB, Christiansen P, Kiss K, Larsen SR, Jespersen ML, Lelkaitis G and Godballe C: Anaplastic thyroid carcinoma in denmark 19962012: A national prospective study of 219 patients. Cancer Epidemiol 53: 65-71, 2018. PMID: 29414634. DOI: 10.1016/j.canep.2018.01.011

16 De Crevoisier R, Baudin E, Bachelot A, Leboulleux S, Travagli JP, Caillou B and Schlumberger M: Combined treatment of anaplastic thyroid carcinoma with surgery, chemotherapy, and 
hyperfractionated accelerated external radiotherapy. Int J Radiat Oncol Biol Phys 60(4): 1137-1143, 2004. PMID: 15519785. DOI: $10.1016 /$ j.ijrobp.2004.05.032

17 Brown RF and Ducic Y: Aggressive surgical resection of anaplastic thyroid carcinoma may provide long-term survival in selected patients. Otolaryngol Head Neck Surg 148(4): 564571, 2013. PMID: 23396588. DOI: 10.1177/019459981 3477364

18 Haymart MR, Banerjee M, Yin H, Worden F and Griggs JJ: Marginal treatment benefit in anaplastic thyroid cancer. Cancer 119(17): 3133-3139, 2013. PMID: 23839797. DOI: 10.1002/ cncr.28187
19 Prasongsook N, Kumar A, Chintakuntlawar AV, Foote RL, Kasperbauer J, Molina J, Garces Y, Ma D, Wittich MAN, Rubin J, Richardson R, Morris J, Hay I, Fatourechi V, McIver B, Ryder M, Thompson G, Grant C, Richards M, Sebo TJ, Rivera M, Suman V, Jenkins SM, Smallridge RC and Bible KC: Survival in response to multimodal therapy in anaplastic thyroid cancer. J Clin Endocrinol Metab 102(12): 4506-4514, 2017. PMID: 29029287. DOI: $10.1210 /$ jc.2017-01180

Received October 1, 2020

Revised October 14, 2020

Accepted October 15, 2020 